International Journal of Instruction e-ISSN: 1308-1470 • www.e-iji.net

Article submission code: 20201024215257

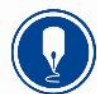

October $2021 \bullet$ Vol.14, No.4

p-ISSN: 1694-609X

pp. 463-482

Received: 24/10/2020

Revision: 27/03/2021
Accepted: 20/04/2021

OnlineFirst: 11/08/2021

\title{
A Regression Analysis Approach to Measuring the Influence of Student Characteristics on Language Learning Strategies
}

\section{Norah Almusharraf}

Asst. Prof., Department of Applied Linguistics, Prince Sultan University, Saudi Arabia, nmusharraf@psu.edu.sa

\section{Daniel R. Bailey}

Asst. Prof., Department of English Language and Literature, Konkuk University (Glocal), South Korea, dbailey0566@kku.ac.kr

Mapping multivariate influence of learner characteristics on behavior highlights models in learning. To this end, we explored the relationships between strategies and learning characteristics and used regression analysis to understand how learner characteristics predict learning strategy choices. A cross-sectional research design with 175 students revealed high levels of strategy use, with statistically significant correlations within and between Strategy Inventory for Language Learning (SILL; Oxford, 1990) and Student Characteristics of Learning (SCL; Artelt, Baumert, Julius-McElvany, \& Peschar, 2003) scales. Regression analyses revealed differences in the types of learner characteristics predicting strategy use, most notably between direct and indirect strategy categories. Instrumental motivation was predictive for both direct and indirect SILL subcomponents, while selfefficacy influenced memory, cognitive and compensation strategies, and persistence predicted reported levels of metacognitive and affective strategy choice. Moreover, a negative path coefficient existed from persistence to compensation strategies and from competition to memory strategies, indicating mediation and overall rich complexity in how learner characteristics influence behavior.

Keywords: foreign language learning, SILL, language learning strategies, learning characteristics, EFL, motivation, self-efficacy, persistence

\section{INTRODUCTION}

Strategic behaviors in learning have appealed to both practitioners and their students ever since they were popularized in the 1970s (Hosenfeld, 1976, 1977; Rubin, 1975; Stern, 1975) as it was widely observed that strategic behavior in good language learners presented a new teaching paradigm. Learning strategies consistently show a positive correlation with the second language (L2) proficiency and successful course outcomes, driving the implementation of strategy training among students studying English as a

Citation: Almusharraf, N., \& Bailey, D. R. (2021). A regression analysis approach to measuring the influence of student characteristics on language learning strategies. International Journal of Instruction, 14(4), 463-482. https://doi.org/10.29333/iji.2021.14428a 
foreign language (EFL; Oxford \& Burry-Stock, 1995). Moreover, strategies are reliable indicators of academic strengths leading to taxonomies of learning strategies developing early in the language learning strategies (LLS) literature (Oxford, 1990a; Rubin, 1981).

Using LLS have been influential in the field because learning is 'situated,' and learning strategies are consequential from a contextual learning environment that includes various factors. For instance, the classroom setting is critical in establishing and determining learner strategies that meet learner needs (Huang, 2016). This is especially significant because foreign languages, among all subjects, are exclusively challenging to learn online (Lin, Zhang, \& Zheng, 2017). Students' active involvement in learning, being driven through a variety of cognitive and metacognitive strategies, is critical to their online learning achievement. Lin et al. (2017) found that online learning strategies functioned at a moderate level in the development of foreign language learning, showing that LLS choice can predict online learning outcomes.

Learning strategy theory has established itself in literature and continues to stay relevant through the idiosyncratic nature of learning environments. Curriculum design influences the LLS that students are trained to use. For instance, interacting with classmates online, watching videos, uploading assignments, attending lessons, or participating in online chat sessions requires different cognitive and behavioral demands. With rapid development in the integration of massive open online courses (MOOCs), few studies have investigated the influence that learning characteristics have on LLS among learners studying EFL in offline settings.

The second set of variables measured here pertain to motivational psychology. The student characteristics for learning (SCL) survey was developed by Artelt, Baumert, Julius-McElvany, and Peschar (2003) and measure instrumental motivation, selfefficacy to use English, persistence, preference for cooperative learning, and preference for competitive learning. Instrumental motivation belongs to an instrumental-integrative dichotomy within the language learning context, and refers to motivation stemming from the desire to learn English out of practical necessity (e.g. earn money, read technical material, or translate documents). Contrarily, integrative motivation pertains to motivation to learn a language for reasons such as interest, attitude, reflecting intrinsic motivation. Self-efficacy refers to beliefs in one's own ability to successfully master learning objectives and affects students' willingness and effort at approaching challenging tasks (Bandura, 1997). Persistence, or grit, refers to long-term perseverance and passion for learning goals, and found to be positively related to students' language learning motivation and achievement (Teimouri, Plonsky, \& Tabandeh, 2020). Learners with a preference for competitive learning enjoy working towards a reward or praise given based on how their performance compares with others. Such competitions can be individual or group and tied to contests with winners and losers. Alternatively, cooperative learning entails teamwork, collaboration, and group thinking to attain learning goals (Johnson \& Johnson, 2009).

There is an abundance of research on LLS and motivational constructs at the univariate level (Han \& Lu, 2018; Tashakori, 2013; Yilmaz, 2010), which connect language learning strategy theory to motivational psychology. Learner characteristics investigated 
in relation to language learning strategy theory at the univariate level include motivation (Nasihah \& Cahyono, 2017; Tashakori, 2013), effort and persistence (Han \& Lu, 2018; Kayaoglu, 2013), self-efficacy (Anam \& Stracke, 2016; Liem, Lau, \& Nie, 2008; Nosratinia, Saveiy, \& Zaker, 2014), and cooperative learning (Likitrattanaporn, 2018). There is a dearth of research exploring how these learning characteristics collectively regress on strategy choice and, consequently, influence our approaches to strategy training. Accordingly, there is now a need for a more comprehensive, multivariate analysis that observes the influence of learning characteristics on language learning strategy choice. To this end, the current research first seeks to identify the relationship between learner characteristics and reported levels of language learning strategies, and secondly, examine the influence that self-efficacy, instrumental motivation, effort and persistence, and preferences for cooperative or competitive learning have on EFL students' language learning strategy choice. To accomplish these aims, the following research questions were asked.

Research Question 1: What relationships emerge between self-efficacy, instrumental motivation, persistence, preferences for cooperative learning, and preferences for competitive learning and reported levels of language learning strategies?

Research Question 2: What are the influences of self-efficacy, instrumental motivation, persistence, preferences for cooperative learning, and preferences for competitive learning on reported levels of language learning strategies?

\section{Literature Review}

Language learning strategies materialized early on in second language acquisition (SLA) literature by Rubin (1975) intending to investigate strategies utilized by successful language learners. Language learning strategies refer to the "specific actions, behaviors, steps, or techniques" employed by learners (Oxford, 2001, p. 44), aiming to improve learners' self-efficacy, self-determination, and persistence (Allwright, 1990; Little, 1991). Language learning strategies are active, chosen, goal-oriented, and purposeful (Oxford, 2017). Specifically, learning strategies are defined as specific behaviors and thought processes used by the learner to facilitate the acquisition, storage, or retrieval of information (Weinstein \& Mayer, 1986). These performances and thought procedures are driven by purpose, intentionally positioned, acquiescent to alteration, and can be observable or unobservable (Wenden, 1998).

The existing body of literature clearly shows a positive correlation between LLS and L2 proficiency (Dreyer \& Oxford, 1996; Han \& Lu, 2018; Jung \& Lee, 2019; Nasihah \& Cahyono, 2017), and researchers agree that proficient learners employ a comprehensive range of strategies. Language learning strategy theory proposes that struggling learners can benefit by adopting strategies used by their more proficient counterparts. Moreover, by creating learning environments conducive to successful LLS, teachers can increase learners' academic abilities and strengthen their willingness to engage in academic tasks through exposure (Margolis \& McCabe, 2006).

Seminal contributions have been made by previous researchers to explore different types of classifications for LLS. Beltrán (1996), for example, has classified learning strategies 
into four categories: (1) support strategies (i.e. motivation, attitudes, and affect), (2) processing strategies (i.e. selection, organization, and processing), and (3) knowledge personalization strategies (i.e. creative and critical thinking, recovery, and transfer). Similarly, O'Malley and Chamot (1990) put forward four categories for learning strategies: cognitive, metacognitive, social, and affective. However, Oxford's (1990a) taxonomy has gained the utmost attention, among these and other classifications. Oxford classifies strategies into two principal categories: offering direct mental support for language learning and providing indirect support for language learning. Oxford's (1990a) SILL direct strategies include memory (i.e. employing action), cognitive (i.e. analyzing and reasoning), and compensation strategies (i.e. overcoming L2 limitations by guessing intelligently). Indirect strategies include metacognitive (i.e. evaluating your learning), affective (i.e. lowing your anxiety), and social strategies (i.e. cooperating with others).

\section{Motivation and Language Learning Strategies}

Language learning strategies consistently show a positive correlation with learner motivation (Tashakori, 2013). Ryan and Deci (2000) define motivation as behavior driven by satisfying internal rewards because of interest or enjoyment (i.e. intrinsic) or driven by a desire from outside influence (i.e. extrinsic). Instrumental motivation is a source of extrinsic motivation that refers to the practical pragmatic reason for language study and places a utilitarian value on learning for career advancement (Simmons, Dewitte, \& Lens, 2000). Khazaie and Mesbah (2014) recognized that both intrinsic and extrinsic motivation influenced the frequency use and choice of reported LLS, with the highest correlation shared with affective strategies $(r=.75$ to $.93, p<.01)$ and the lowest correlation shared with memory strategies $(r=.23$ to $.54, p<.01)$. Moreover, results from a survey study by Shin and So (2018) revealed that higher levels of determination, mastery goal orientation, and internal regulation positively affected the use of cognitive, metacognitive, compensatory, and social strategies.

Similarly, Nasihah and Cahyono (2017) found a positive correlation between motivation and LLS. When LLS and motivation were added to the same regression model, they both predicted achievement in L2 writing performance (2017). Furthermore, Teng and Zhang (2018) revealed that students described the use of motivational regulation strategies as helpful in sustaining, initiating, and developing their inclination and effort to complete a task. These findings provide evidence for a clear relationship between motivation and the use of various LLS. The more motivated students are, the more strategies they tend to use (Chang \& Liu, 2013; Xu, 2011). Instrumental motivation among Saudi EFL students has been reported at higher levels than intrinsic motivation (Ahmad, 2016; Moskovsky, Alrabai, Paolini, \& Ratcheva, 2013), but exactly how instrumental motivation relates to the choice of learning strategies is unclear.

\section{Persistence and Language Learning Strategies}

Persistence (i.e. perseverance or grit) is positively associated with mastery goals and studying strategies and entails sustained effort for a particular long-term goal (Maddi, 2006). This persistence of effort promotes the overcoming of obstacles or challenges 
that lie in between the learner and the learning goal (Grant \& Dweck, 2003). Among learner characteristics, persistence is one of the less-studied student characteristics in the context of LLS (Han \& Lu, 2018; Kayaoglu, 2013). Having a strong commitment to completing goals is a crucial attribute of persistence and an antecedent to essential features of LLS, including planning, regulating learning, and seeking help from others. Emerging literature shows a strong connection between persistence and LLS choice. For instance, among a group of 193 students, Han and Lu (2018) found that such commitment to goals showed a positive correlation with LLS with all but the affective LLS positively correlated to goal setting and achievement motivation. Cognitive, compensation, and metacognitive strategies revealed the highest correlation with goalsetting metrics (e.g. specific goals, a strong commitment to goals, and mastery goals). Furthermore, task persistence, as a learning factor, was found to be strongly associated with knowledge progress, attitudes, and skills development among 94 Japanese learners (Jung \& Lee, 2019).

\section{Self-Efficacy and Language Learning Strategies}

Language learning self-efficacy is the next learner characteristic of interest and is defined as confidence in one's own ability to achieve intended results, and consequently, a proven predictor of performance (Bandura, 1997). Self-efficacy consistently predicts positive learning outcomes related to academic performance, domain knowledge, and learner engagement (Bong, 2001; Liem et al., 2008) and is considered an essential motive to learn (Zimmerman, 2000).

Research in the field of self-efficacy has shown that students with stronger self-efficacy beliefs for a general subject or specific task have a propensity to achieve at higher levels within that domain or on that task in comparison to students with lower levels (Bandura, 1997). Further, findings from previous studies (Teng \& Zhang, 2016; Teng \& Zhang, 2018) showed clear associations between self-efficacy beliefs (e.g. perceived abilities) in self-regulated learning (thoughts and actions that affect learning) in strategy usage.

Several studies have explored the influence of self-efficacy on LLS and consistently describe a positive association (Anam \& Stracke, 2016; Liem et al., 2008; Nosratinia et al., 2014). The positive correlation between self-efficacy and LLS use has not gone unchallenged. Anam and Stracke (2016) found no relationship among a group of 130 participants' LLS use and self-efficacy at learning English. Despite the lack of statistical significance among Anam and Stracke's (2016) students, overwhelming evidence suggests self-efficacy strongly predicts LLS use (Magogwe \& Oliver, 2007; Wong, 2005; Yilmaz, 2010). The most prominent correlation perhaps was found by Nosratinia et al. (2014) when they explored the relationships among LLS, general academic selfefficacy, and metacognitive awareness among a group of 143 English translation majors and calculated Pearson $r$ values above $.70(p<.001)$ between self-efficacy and all six SILL subcomponents.

\section{Cooperation-Competition and Language Learning Strategies}

Chen (2018) has confirmed that a cooperative approach to learning helps develop engagement in the classroom through problem-solving with the input of the whole 
group. Cooperative learning also increases students' awareness, understanding of subject matter, and regulation of the process of acquiring knowledge that is needed for ideal learning outcomes. Cooperative learning is a kind of instructional technique in which teachers organize students into small groups, which then work together to help one another achieve learning goals (Slavin, 2011) and has been linked to increased engagement (Chen, 2018) and increased gains in academic performance (Johnson \& Johnson, 2009; Yusuf, Jusoh \& Yusuf, 2019). A quasi-experimental study was carried out to investigate the effects of cooperative learning on learning strategies of 72 secondyear Vietnamese university students. Students following cooperative learning instruction reported increased levels of cognitive and metacognitive strategies. At the same time, the control group showed no changes in strategy choice or frequency of strategy use, with the most significant increase in strategy use among students in the experimental group in help-seeking and peer learning behavior (Tran, Nguyen, Van De, Soryaly, \& Doan, 2019). Similarly, another cross-sectional survey study result revealed that students who preferred cooperative learning over studying language alone used more cognitive, metacognitive, and social LLS (Zhou \& Intaraprasert, 2019).

As described above, the SILL has been used to model the relationship between learner characteristics and learning strategies; however, a limitation with these studies is that learner characteristics are analyzed at the univariate level, separate from one another. The following methods were taken to contribute to LLS theory by helping explain how learner characteristics uniquely influence direct (memory, cognitive, and compensation) and indirect (metacognitive, affective, and social) strategies.

\section{METHOD}

In this cross-sectional survey study, the relationship between LLS and learning characteristics were explored. In educational research, a cross-sectional study is a type of observational study that analyzes data from a subset of a population at a specific time. The specific point occurred in the Kingdom of Saudi Arabia (KSA), where there are only a few institutions that operate entirely online, allowing coeducational classes (Al-Ghaith, Sanzogni, \& Sandhu, 2010). Thus, this study is unique in its nature as it was entirely online and in a mixed-gender classroom, which is not the norm in KSA (Alrashidi \& Phan, 2015).

\section{Context and Participants}

Within this study, Saudi EFL learners were examined synchronously in the online platform (Blackboard). A total of 175 undergraduates (51 males and 124 females) EFL junior and senior undergraduate students were recruited from the English department in one public university in the KSA. All participants were enrolled in one of one synchronously run section of a 3rd-year English literature course. The purpose of which was to prepare students to understand cultural, social, historical, and political issues elevated by the literature. The 6-week course was designed for non-native English learners, was worth three credits, and ran three times a week for 2 hours each time. Students were recruited from the English Department's Preparatory Year Program. possessed intermediate to advanced L2 proficiency levels, ranging between B1 and C1 of the Common European Framework of Reference (CEFR) as measured by a minimum 
IELTS (5.5) or TOEFL (46-59) score prior to joining the English Department's Preparatory Year Program, indicating at least modest levels of English competency.

\section{The Instruments}

Two questionnaires were employed during data collection, which were the Strategy Inventory for Language Learning (SILL) and Student Characteristics as Learners (SCL) questionnaires. The SILL, developed by Oxford (1990b), was administered to examine language strategy use. Six strategy fields are involved in the questionnaire: memory (items 1-9), cognitive (items 10-23), compensation (items 24-29), metacognitive (items 30-38), affective (items 39-44), and social (items 45-50) strategies. The participants' responses were documented on a 5-point Likert scale (1, never or almost never true of me to 5 , to always or almost always true of me). When interpreting results, Oxford (1990a) suggests a mean of 1.0 to 2.4 and lower for "low," a mean range of 2.5 to 3.4 for "medium," and a mean range of 3.5 to 5.0 for "high" levels of strategy use.

The SCL (Artelt, Baumert, Julius-McElvany, \& Peschar, 2003) analyzed student characteristics as learners. Although the questionnaire has undertaken several modifications and adaptations in recent years, the framework is still valid. The questionnaire scales consist of instrumental motivation (items 1-3), persistence in learning (items 4-7), self-efficacy (items 8-11), preference for cooperative learning (items 12-16), and preference for competitive learning (items 17-20). Students were asked to give their responses on a 5-point Likert scale (1, almost never to 5, almost always; 1 , strongly disagree to 5 , strongly agree). The reliability coefficients were above the recommended value of .70 (Taber, 2018), ranging between 0.73 and 0.87 for the SILL and between 0.78 and 0.87 for the SCL categories (see Table 1), which are similar reliability scores observed earlier by Artelt et al. (2003, p. 84) when administering the same survey in a cross-cultural study of OECD countries.

The survey was created and distributed using the LimeSurvey online platform, in which the link was sent to their emails and to the Whatsapp group where all the class was gathered. The survey items were explained in advance to ensure students' understating of each item. The survey was made available to participants at the end of the summer term in July 2020 and was kept open until August 2020 (8 weeks), at which time the researcher determined that no further responses were likely forthcoming. Within the welcome message in the online survey, survey participants were informed that completion of the survey implied their consent to participate in this research. While the instructor reminded the participants to do the survey (outside the class time) before getting their quiz grades, the students were informed that the survey result would be only obtainable by the researcher herself, and the instructor had no access to the data. Participants were given time to complete the survey to ensure they answered the questions appropriately and freely. Further, participants were informed that data were confidential and that all personal information would be de-identified, and no extra credit was rewarded to them.

\section{Data Analysis}

Data were analyzed using IBM SPSS (version 24.0). Mean score and Pearson correlation results were used to measure the magnitude and relation of the variables of 
interest. A series of multiple linear regression analyses were used to explore the influence that different student characteristics have on strategy choice. Multiple linear regression is a technique used when there is more than one explanatory variable and where multiple dependent variables are predicted (Mardia, Kent, \& Bibby, 1979). A series of six separate multiple linear regression analyses were carried out, one for each SILL category. Initially, Cook's Distance and Mahalanobis Distance were calculated for each survey to find influential outliers in which 8 existed and were consequently removed. Collinearity diagnostics for learning strategy subscales, involved instrumental motivation, effort, persistence in learning, self-efficacy, preference for cooperative learning, and competitive learning were measured. The correlations among SILL and SCL variables were significant and high; however, no collinearity effect was detected. All VIF values for the SILL and SCL subcomponents ranged between 1.96 and 4.58, below the recommended maximum level of 10 (Hair, Anderson, Taham, \& Black, 1995). Further, tolerance levels ranged between .227 and .508 , above the cut-off point of .20 (Weisburd \& Britt, 2013).

\section{FINDINGS}

Research question 1 begins by exploring the strategy choice and student characteristics as determined by the LLS and SLA. Table 1 shows the relationships and mean scores for the variables of interest. The Pearson correlations between SILL and SLA categories, along with mean scores, are displayed. Strategy categories shared a strong correlation with each other $(r>.50, p<.001)$, with the cognitive strategy category having the highest correlations with compensation, metacognitive, and social strategy categories. Means scores for all strategy categories were all above 3.5, indicating high levels of direct and indirect strategy use (Oxford, 1990a). Correlation between gender and LLS choice was measured. Females reported moderately higher levels of strategy use than males, in accordance with past, and ever-growing findings (Khazaie \& Mesbah, 2014; Oxford, 1993; Oxford \& Nyikos, 1989), indicating males lag behind females in the breadth of strategy use.

Lower Pearson $r$ correlation scores were reported for student characteristics than what was observed among the SILL strategy categories. For SLA, statistically significant correlations existed across all relationships except for compensation, which showed the least shared correlation with other variables. Self-efficacy showed the highest correlation with other learner characteristics, with competition having the least (see Table 1). Concerning the SCL scales, the following results can be found: involved instrumental motivation was the highest $(M=4.52, S D=0.77)$, followed by effort and persistence, suggesting that these types of learning characteristics are influential decision-makers. The results for the preference for cooperation were the lowest in this sample, with a mean score of $3.53(S D=0.79)$. It should be noted that while lowest, anything above 3.5 is still considered contributory towards influencing the choices students to take in learning. Research question one further document the the wide use of language learning strategy use among Saudi students and depth of learning characteristics, particularly motivation beliefs for language learning stemming from practical rewards related to finding future employment. Research question two goes on to examine how learning characteristics predict learning strategies. 
Table 1

Correlations and mean scores for study variables $(\mathrm{n}=175)$

\begin{tabular}{|c|c|c|c|c|c|c|c|c|c|c|c|c|c|c|}
\hline & & Age & $\mathrm{M} / \mathrm{F}$ & 1 & 2 & 3 & 4 & 5 & 6 & 7 & 8 & 9 & 10 & 11 \\
\hline 1 & Mem & .08 & $.25^{*}$ & & & & & & & & & & & \\
\hline 2 & Cog & .09 & .15 & $.60^{* *}$ & & & & & & & & & & \\
\hline 3 & Comp & .03 & $.23^{* *}$ & $.52^{* *}$ & $.80^{* *}$ & & & & & & & & & \\
\hline 4 & Meta & .11 & $.21^{*}$ & $.63^{* *}$ & $.69^{* *}$ & $.61^{* *}$ & & & & & & & & \\
\hline 5 & Aff & $.19^{* *}$ & $.22^{* * *}$ & $.66^{* *}$ & $.53^{* *}$ & $.53^{* *}$ & $.64^{* *}$ & & & & & & & \\
\hline 6 & Soc & .05 & $.20^{* * *}$ & $.59^{* * *}$ & $.73^{* *}$ & $.55^{* *}$ & $.63^{* *}$ & $.61^{* * *}$ & & & & & & \\
\hline 7 & Mot & .01 & .15 & $.38^{* *}$ & $.59^{* *}$ & $.53^{* *}$ & $.63^{* *}$ & $.31^{* * *}$ & $.57^{* *}$ & & & & & \\
\hline 8 & Pers & $.16^{*}$ & .17 & $.53^{* *}$ & $.49^{* *}$ & $.38^{* *}$ & $.66^{* *}$ & $.49^{* *}$ & $.55^{* *}$ & $.62^{* *}$ & & & & \\
\hline 9 & $\mathrm{SE}$ & .09 & $26^{*}$ & $.61^{* *}$ & $.52^{* *}$ & $.49^{* *}$ & $.60^{* *}$ & $.49^{* *}$ & $.49^{* *}$ & $.50^{* *}$ & $.74^{* *}$ & & & \\
\hline 10 & Coop & .04 & .05 & $.34^{* *}$ & $.26^{* *}$ & $.23^{* *}$ & $.36^{* *}$ & $.41^{* * *}$ & $.34^{* *}$ & $.18^{*}$ & $.34^{* *}$ & $.45^{* *}$ & & \\
\hline \multirow[t]{4}{*}{11} & Comp & .02 & .02 & -.15 & $.15^{*}$ & $.20^{* * *}$ & $.17^{*}$ & .14 & $.26^{* *}$ & $.25^{* * *}$ & $.19^{*}$ & -.04 & $.20^{* *}$ & \\
\hline & $\alpha$ & & & .87 & .85 & .73 & .80 & .74 & .81 & .87 & .83 & .79 & .78 & .88 \\
\hline & Mean & 1.94 & 1.7 & 3.80 & 3.92 & 3.85 & 4.08 & 3.72 & 3.94 & 4.52 & 4.38 & 4.14 & 3.53 & 3.83 \\
\hline & SD & .517 & 0.46 & 0.79 & 0.62 & 0.68 & 0.65 & 0.70 & 0.78 & 0.77 & 0.69 & 0.79 & 0.79 & 0.89 \\
\hline
\end{tabular}

Note: $* \mathrm{p}<.05, * * \mathrm{p}<.01 ;$ Male $=1$, Female $=2 ;$ Mem, memory; Cog, cognitive; Comp,

compensation; Meta, metacognitive; Aff, affective; Soc, social; Mot, instrumental motivation; Pers, persistence; SE, academic self-efficacy; Coop, preference for cooperation; Comp, preference for competition.

\section{Research Question 2}

Research question 2 uses multiple linear regression to examine the influence of SCL variables on each of the six LLS categories. Table 2 displays standardized beta weights and significant values from regression models. A series of multiple linear regressions were carried out to predict the reported choice of memory strategies based on motivation, self-efficacy, persistence in learning, preference for cooperative learning, and preference for competitive learning. For the memory category, a significant regression equation was found $(F(5,169)=26.40, \mathrm{p}<.001)$, with an adjusted $R^{2}$ of .422. Participants' predicted use of memory strategies is equal to 1.25 (constant) +.314 $($ self-efficacy) +.254 (persistence) +.145 (cooperation) - .208 (competition), where SLA variables are measured from 1 (strongly disagree) to 4 (strongly agree). Participants' use of memory strategies increased .315 points for each 1 point increase in self-efficacy, .223 for each 1 point increase in persistence, and .145 points for each 1 point cooperation. Conversely, there was a decrease of .208 points for each 1 point increase in competition, indicating a negative path coefficient.

For the cognitive category, a significant regression equation was found $(F(5,169)=$ $24.86, \mathrm{p}<.001$ ), with an adjusted $R^{2}$ of .407 . Participants' predicted use of cognitive strategy use is equal to 1.205 (constant) +.358 (motivation) +.238 (self-efficacy). Participants' use of cognitive strategies increased .358 points for each 1 point increase in motivation and .238 for each point increase in self-efficacy. 
Table 2

Regression analysis with SCL variables as predictors of LLS choice

\begin{tabular}{|c|c|c|c|c|c|c|c|c|}
\hline & $B$ & $S E$ & Beta & $t$ & $p$ & $F$ & $R^{2}$ & Adj. $R^{2}$ \\
\hline Memory & 1.125 & .354 & & 3.178 & $.002^{* * *}$ & 26.4 & .439 & .422 \\
\hline Motivation & .121 & .079 & .117 & 1.538 & .126 & & & \\
\hline Persistence & .254 & .112 & .223 & 2.261 & $.025^{*}$ & & & \\
\hline Self-efficacy & .314 & .099 & .314 & 3.191 & $.002^{* * *}$ & & & \\
\hline Cooperation & .145 & .068 & .145 & 2.145 & $.033^{*}$ & & & \\
\hline Competition & -.208 & .058 & -.233 & -3.574 & $.000^{* * *}$ & & & \\
\hline Cognitive & 1.205 & .279 & & 4.318 & $.000^{* * *}$ & 24.86 & .424 & .407 \\
\hline Motivation & .358 & .062 & .444 & 5.776 & $.000^{* * *}$ & & & \\
\hline Persistence & -.034 & .089 & -.039 & -.388 & .698 & & & \\
\hline Self-efficacy & .238 & .078 & .306 & 3.068 & $.003^{\text {*** }}$ & & & \\
\hline Cooperation & .038 & .053 & .049 & .720 & .472 & & & \\
\hline Competition & .034 & .046 & .048 & .732 & .465 & & & \\
\hline Compensation & 1.150 & .315 & & 3.650 & $.000^{* * *}$ & 21.36 & .387 & .369 \\
\hline Motivation & .364 & .070 & .413 & 5.207 & $.000^{* * *}$ & & & \\
\hline Persistence & -.264 & .100 & -.271 & -2.633 & $.009^{* * *}$ & & & \\
\hline Self-efficacy & .421 & .088 & .494 & 4.805 & $.000^{* * *}$ & & & \\
\hline Cooperation & -.009 & .060 & -.011 & -.155 & .877 & & & \\
\hline Competition & .128 & .052 & .169 & 2.476 & $.014^{*}$ & & & \\
\hline Metacognitive & .637 & .262 & & 2.437 & $.016^{*}$ & 41.07 & .549 & .535 \\
\hline Motivation & .301 & .058 & .353 & 5.189 & $.000^{* * *}$ & & & \\
\hline Persistence & .267 & .083 & .284 & 3.215 & $.002^{* * *}$ & & & \\
\hline Self-efficacy & .127 & .073 & .154 & 1.740 & .084 & & & \\
\hline Cooperation & .103 & .050 & .124 & 2.053 & $.042^{*}$ & & & \\
\hline Competition & .008 & .043 & .010 & .176 & .860 & & & \\
\hline Affective & 1.030 & .342 & & 3.014 & $.003^{* * *}$ & 15.98 & .321 & .301 \\
\hline Motivation & -.006 & .076 & -.006 & -.074 & .941 & & & \\
\hline Persistence & .258 & .109 & .257 & 2.378 & $.019^{*}$ & & & \\
\hline Self-efficacy & .180 & .095 & .205 & 1.890 & .060 & & & \\
\hline Cooperation & .191 & .065 & .217 & 2.927 & $.004^{* * *}$ & & & \\
\hline Competition & .043 & .056 & .056 & .774 & .440 & & & \\
\hline Social & .143 & .351 & & .408 & .684 & 25.29 & .428 & .411 \\
\hline Motivation & .347 & .078 & .342 & 4.467 & $.000^{* * *}$ & & & \\
\hline Persistence & .157 & .111 & .140 & 1.410 & .160 & & & \\
\hline Self-efficacy & .163 & .098 & .166 & 1.668 & .097 & & & \\
\hline Cooperation & .128 & .067 & .131 & 1.914 & .057 & & & \\
\hline Competition & .108 & .058 & .123 & 1.868 & .063 & & & \\
\hline
\end{tabular}

Note: ${ }^{*} p<.05,{ }^{* *} p<.01$

Next, the compensation category revealed a significant regression equation $(F(5,169)=$ 21.36, $\mathrm{p}<.001)$, with an adjusted $R^{2}$ of .369. Participants' predicted use of compensation strategies is equal to 1.115 (constant) +.364 (motivation) +.421 (selfefficacy) +.169 (competition) - .264 (persistence) - .128 (competition). Participants' use of compensation strategies increased .364 points for each 1 point increase in motivation and .421 for each 1 point increase in self-efficacy, and .169 in competition, but decreased .264 points for each point increase in persistence. While it was expected that a positive relationship noticed from Table 1 would continue with the regression analysis, 
the negative path coefficient between persistence and compensation strategies was unexpected and clear evidence of a negative mediation effect worth exploring furth.

Moving on to indirect strategy categories, we begin with the metacognitive subcomponent in which a significant regression equation was found $(F(5,169)=41.07$, $\mathrm{p}<.016)$, with an adjusted $R^{2}$ of .535 . Participants' use of metacognitive strategies increased .353 for each point increase in motivation, .284 for each point increase in persistence, and .124 for each point increase in the cooperative learning scale. For the affective strategy category, a significant regression equation was found $(F(5,169)=$ $15.98, \mathrm{p}<.003$ ), with an adjusted $R^{2}$ of .301. Participants' use of affective strategies increased .257 and .217 for each point increase in persistence and cooperation, respectively, indicating cooperation is more relevant to indirect LLS strategies than direct ones. The final category was social strategies in which only instrumental motivation showed a statistically significant path coefficient $(\mathrm{b}=.342, p<.001)$.

For direct LLS, motivation and self-efficacy revealed themselves to be significant predictors of cognitive strategies. Similarly, motivation and self-efficacy were also predictors of compensation, indicating the importance of enthusiasm and confidence when learning, practicing, and teaching direct LLS. When added to the regression model, persistence had a negative influence on compensation LLS. Compensation strategies entail making guesses to fill knowledge gaps and consequently avoid needing the persistence to look up new words or ask others for help. Less proficient L2 learners are likely to rely on compensating for their lack of knowledge and therefore fall back on such strategies instead of ones that require more effort.

Learning characteristics as predictors showed a different pattern of influence on indirect LLS strategies. For metacognitive strategies, persistence and motivation were the strongest predictors, followed by cooperation. For affective strategies, cooperation and persistence were the significant predictors, and only motivation produced a significant beta weight coefficient for social LLS. While self-efficacy was a strong predictor for direct LLS, persistence was a uniquely strong predictor for indirect LLS. Overall, instrumental motivation appears to be predictive for both direct and indirect strategy use. We now attempt to situate these findings in the context of previous language learning strategy research.

\section{DISCUSSION}

Findings not only highlight how student characteristics work in unison to influence strategy choice, but how those characteristics influence strategy choice differently. Instrumental motivation showed the most statistically significant positive paths to language learning strategy categories, establishing its place as a primary factor in predicting second language acquisition among adult EFL learners. Persistence showed three statistically significant positive path coefficients with direct strategy categories, with one negative path to the compensation strategy category, indicating mediation. Self-efficacy was a strong predictor for direct strategy categories (i.e. memory, cognitive, and compensation). Finally, only instrumental motivation predicted the reported use of social language learning strategies. We now attempt to explain the 
findings from research questions one and two within the framework of the language learning strategy theory.

Research question one examined the relationship between LLS and learner characteristics. Results affirm that strategy use significantly influences the different factors of foreign language learning and students' learning approaches. Explicitly, Pearson correlation analysis confirmed positive relationships within and between SLA and SILL categories, barring a few exceptions with the competition scale. Thus, the results echo previous research that shows cooperative learning preferences are conducive to LLS training (Zhou \& Intaraprasert, 2019). The strategies a student chooses to learn a second language are mainly centered on the individual learning characteristics; some students are more engaged in communicative and cooperative contexts and others prefer individual work. Contrarily, competition plays a smaller role when choosing learning strategies. In light of this finding of a positive correlation between motivation and other SILL strategy categories, instrumental motivation is a key antecedent to language learning in the English class, which may, in turn, develop students' skills within and beyond the learning environment.

Cooperation and competition are associated with learner autonomy; students must recognize their learning through metacognition, initiate and collaborate with others, and eventually engage in communicating with other members. Throughout the process, the instructors play a significant role in promoting classroom motivation by familiarizing levels of cooperation and competition in the classroom and addressing the needs of utilizing different strategies of learner engagement (Atashian \& Zamini, 2013; Zarei \& Layeq, 2016).

Moreover, the results demonstrated that the surveyed group of students in this study reported using high levels of strategies for all categories, with mean scores in the highlevel range ( $M=3.5$ to 5.0) of strategy use (Oxford, 1990a). This result ties in well with previous studies (Alhaysony, 2017) wherein it was found that cognitive, metacognitive, and compensation strategies were used most frequently by Saudi EFL learners. Furthermore, female participants in this current study used more LLS than males, which is consistent in the LLS literature (Alhaysony, 2017; Khazaie \& Mesbah, 2014; Mochizuki, 1999; Oxford \& Nyikos, 1989). Likewise, participants reported elevated levels of student learning characteristics, with instrumental motivation rated higher than the other SLA variables. High levels of instrumental motivation echo findings within a similar learning context of Saudi EFL students (Altasan, 2016; Moskovsky, C., Alrabai et al., 2013), recognizing that the monetary reward through practical use of English is of considerable importance among the students.

Research question two measured the influence of self-efficacy, instrumental motivation, persistence, and preferences for cooperative and competitive learning on each of the language learning strategy categories. The findings revealed that for the memory category, self-efficacy, persistence, and cooperative learning behavior predicted higher strategy use (e.g. visualizing concepts, connecting sounds, reading aloud). Interestingly, competition showed a significant negative influence. The reasoning for the negative path coefficient might be that motivation by competition is not conducive to LLS training 
because language learning from a sociocultural view places importance on meaningful interactions among individuals, attributing to the most significant motivational force in learning (Vygotsky, 1978). The findings of this study are inconsistent with Khazaie and Mesbah's (2014) results, in which the highest correlation among SILL categories were shared with affective strategies and the lowest correlations were shared with memory strategies. This inconsistency is attributed to not taking into consideration multiple factors that predict strategy choice.

In regards to the cognitive category model, both motivation and self-efficacy showed statistically significant path coefficients in the model for cognitive LLS. This is a clear indication that self-efficacy is a strong predictor for direct LLS, supporting previous findings (Anam \& Stracke, 2016; Liem et al., 2008; Nosratinia et al., 2014). Similar to cognitive LLS, self-efficacy and motivation are positive predictors of compensation strategies.

Further conflict with past research can be seen concerning persistence (Han \& Lu, 2018) which also shared a negative path coefficient with the compensation strategy category. When added to the compensation model, the positive Pearson $r$ correlation seen in Table 1 was reduced to a statistically significant negative path coefficient $(b=-2.71, p=.009)$, indicating a mediation effect. A possible explanation for the negative path between persistence and compensation strategies may lie in how compensation strategies are used. Compensation strategies are used less frequently among high proficient L2 speakers (Mochizuki, 1999) and this could be due to such speakers having fewer knowledge-gaps and more persistence to look-up unknown words. Contrarily, their lower achieving counterparts may be unwilling to put forth effort in looking up unknown words or asking others for help. To elaborate, compensation strategies can work in the positive when used by more advanced learners who have a wider vocabulary to use when compensating for knowledge-gaps; however, less advanced L2 learners resort to compensation strategies to avoid putting in the effort to build new knowledge.

Student characteristics influence indirect SILL strategy categories (i.e. metacognitive, affective, and social) slightly differently than direct SILL strategy categories (i.e. memory, cognitive, and compensation). Concerning metacognitive strategies, motivation, persistence, and to a lesser extent, cooperation help explains the driving forces behind their use. The findings pertaining to persistence and metacognitive strategies were in accordance with extant literature (Han \& Lu, 2018; Jung \& Lee, 2019; Kayaoglu, 2013) which highlights the importance of persistence when planning, regulating learning, and seeking help from others.

In regards to affective LLS, cooperation and persistence both showed positive path coefficients with affective strategy use. Affective strategies entail that students manage their emotions and are valuable for apprehensive students. When learners are strongly committed to reaching their goals, they show the quality of persistence in LLS, including preparation, adaptation, and looking for support from others.

Social strategies can be described as a tendency to want to practice English actively with others, and the choice to use social LLS was predicted by instrumental motivation. 
Language learning is collaborative and social LLS are arguably the most important because the end goal is often to use the target language with others.

The current study findings are in agreement with other studies that also demonstrated that LLS, specifically cognitive, compensation, metacognitive and social strategies, provide evidence for a clear relationship between instrumental motivation and the use of various LLS. (Moskovsky, Racheva, Assulaimani, \& Harkins, 2016). Students with the clear need for their learning goal, preferably an internal need beyond just attaining a passing score, may be expected to have heightened levels of motivation and, therefore, a more reliable drive to interact with others. Further, the current study is directly in line with previous findings from Shin and So (2018), which indicated that higher levels of determination, mastery goal orientation, and internal regulation positively affected the use of cognitive, metacognitive, compensation, and social strategies. Specifically, the learners' desire for career advancements, instrumental motivation, dominated decision making in strategy choice. The more motivated students are, the more strategies they tend to use (Alhaysony, 2017; Chang \& Liu, 2013; Xu, 2011).

Similar to our results, previous literature shows a strong connection between persistence and LLS choice (e.g. Han \& Lu, 2018; Jung \& Lee, 2019), particularly with goal-setting metrics (e.g. specific goals, a strong commitment to goals, and mastery goals). Furthermore, task persistence, as a learning aspect, was found to be strongly connected with knowledge progress, attitudes, and skills development among EFL learners. Instructors can influence classroom motivation by introducing levels of cooperation and competition in the classroom (Zarei \& Layeq, 2016) and prompt activity that allow learners to be persistent and increase different strategies of learner engagement (Atashian \& Zamini, 2013). The results provide valuable input to the applied field of foreign language learning and further explore characteristics of language acquisition. It also takes into consideration the various cognitive and noncognitive (i.e. affective and social factors) that can significantly support learners in becoming self-directed, productive, and successful language learners.

\section{CONCLUSIONS}

The findings of this present research offer a clear indication of the construction of specific significant characteristics of language learning and its influence on strategy use. This survey study confirmed the strong relationship between second LLS choice and their learning characteristics that aligns with motivational strategies such as selfefficacy, instrumental motivation, persistence, and preferences for cooperative or competitive learning. Efficacious students who eagerly apply for metacognitive, cognitive, memory, social, compensation, or affective strategies are capable of designing their learning objectives more assuredly and reflect on their learning process more deliberately.

However, the present study encountered several limitations, which naturally include applying only two instruments to evaluate EFL Saudi learners' perceptions of learner characteristics. Future research needs to employ both qualitative methods (e.g. classroom observations and interviews) and quantitative methods (e.g. performance tests) that would aid to get an insider view of the learners' interactions and perceptions 
and would allow for more insights into how students use these strategies and other types of strategies not captured by the SILL. This study was not intended to measure the effectiveness of particular strategy use, only the occurrence of use and how that use was influenced by learner characteristics were investigated.

Further, the sample size for the research is limited to one public school in KSA; consequently, a generalization of the findings might not be appropriate in other contexts, age groups, or educational levels. Also, within this study, the emerging findings of the confounding variables like age and gender could not be taken into consideration, as the data did not confirm that. More research on factors that influence strategy choice is highly suggested. While the variables included in the current study may elucidate some of the differences in reported strategy use among the EFL learners, other factors (e.g. language aptitude, views, social and cultural background, motivation, attitude, and personality) might have significant effects and consequences.

The current study offers several implications. The reviewed literature indicated a paucity of research on EFLs within the Middle East context in general and Saudi EFL specifically. Further research, including descriptive, experimental, and cross-sectional studies, is thus suggested to develop an understanding of Saudi EFL students' employment of LLS. Further, there is a critical need to integrate strategy training for instructors and learners into the foreign language classroom. The findings of this study could be utilized for instructional drive and curriculum development.

Overall, it can be revealed from the emerging data that LLS is a useful tool for assisting students in bridging communication gaps. As Namaziandost, Imani, and Ziafar (2020) argue, by learning different techniques and a set of core expressions, students became more confident in their ability to communicate, even in situations where they do not fully understand all the language. The undertaken study sheds light on the application of different LLS for resolving learners' oral and written communication issues. It further could aid EFL learners to acquire and progress through the English language more efficiently and, eventually, develop self-awareness of their learning processes.

Further examinations should also reflect on pedagogical implications. Taking our results into account, if they occur to coincide with the results in other parallel research studies, EFL institutions should consider implementing the needed measures to eliminate gender differences, and both males and females counterparts should feel more self-assured and driven and engaged.

\section{ACKNOWLEDGMENTS}

The authors would like to thank Prince Sultan University (PSU) for funding this research project and in affiliation with Educational Research Lab. In addition, this paper was supported by Konkuk University in 2021.

\section{REFERENCES}

Ahmad, M. B. A. (2016). Motivational orientations and their effect on English Language Learning: A Study in EFL Saudi Context. American Journal of Educational Research, 4(16), 1131-1137. https://doi.org/10.12691/education-4-16-2. 
Al-Ghaith, W., Sanzogni, L., \& Sandhu, K. (2010). Factors influencing the adoption and usage of online services in Saudi Arabia. The Electronic Journal of Information Systems in Developing Countries, 40(1), 1-32. https://doi.org/10.1002/j.1681-4835.2010.tb00283.x

Alhaysony, M. (2017). Language learning strategies use by Saudi EFL students: The effect of duration of English language study and gender. Theory and Practice in Language Studies, 7(1), 18-28. http://dx.doi.org/10.17507/tpls.0701.03

Allwright, D. (1990). Autonomy in language pedagogy. CRILE Working Paper 6. Lancaster: University of Lancaster, Centre for Research in Education.

Alrashidi, O., \& Phan, H. (2015). Education context and English teaching and learning in the Kingdom of Saudi Arabia: An overview. English Language Teaching, 8(5), 3344. http://dx.doi.org/10.5539/elt.v8n5p33

Anam, S., \& Stracke, E. (2016). Language learning strategies of Indonesian primary school students: In relation to self-efficacy beliefs. System, 60, 1-10. https//doi.org/10.1016/j.system.2016.05.001

Artelt, C., Baumert, J., Julius-McElvany, N., \& Peschar, J. (2003). Learners for life: Student approaches to learning: Results from PISA 2000. OECD Publishing. https://doi.org/10.1787/9789264103917-en

Atashian, S., \& Zamini, S. (2013). The effects of cooperative language learning on Iranian EFL learners strategy use. Global Journal of Foreign Language Teaching, 1, 09-14. http://archives.un-pub.eu/index.php/GJFLT/article/viewArticle/2043

Bandura, A. (1997). Self-efficacy: The exercise of control. New York: Worth Publishers.

Beltran, J. A. (1996). Concept, development, and current trends of instructional psychology. In J. Beltran \& C. Genovard (Eds), Instructional psychology (pp. pp. 1986). Madrid: Sintesis.

Bong, M. (2001). Between- and within-domain relations of academic motivation among middle and high school students: Self-efficacy, task-value, and achievement goals. Journal of Educational Psychology, 93(1), 23-34. https://doi.org/10.1037/00220663.93.1.23

Chang, C., \& Liu, H. (2013). Language learning strategy use and language learning motivation of Taiwanese EFL university students. Electronic Journal of Foreign Language Teaching, 10(2), 196-209. https://e-flt.nus.edu.sg/v10n22013/chang.pdf

Chen, Y. (2018). Perceptions of EFL college students toward collaborative learning. Canadian Center of Science and Education, 11(2), 1-4. https://doi.org/10.5539/elt.v11n2p1

Dreyer, C., \& Oxford, R. L. (1996) Learning strategies and other predictors of ESL proficiency among Afrikaans speakers in South Africa. In R. L. Oxford (Ed.), Language learning strategies around the world: Cross-cultural perspectives. (pp. 61-74). Honolulu: University of Hawaii, Second Language Teaching \& Curriculum Center. 
Grant, H., \& Dweck, C. S. (2003). Clarifying achievement goals and their impact. Journal of Personality and Social Psychology, 85(3), 541-553. https://doi.org/10.1037/0022-3514.85.3.541

Hair, J. F. Jr., Anderson, R. E., Tatham, R. L., \& Black, W. C. (1995). Multivariate data analysis (3rd ed). New York: Macmillan.

Han, J., \& Lu, Q. (2018). A correlation study among achievement motivation, goalsetting and L2 learning strategy in EFL context. English Language Teaching, 11(2), 514. http://doi.org/10.5539/elt.v11n2p5

Hosenfeld, C. (1976). Learning about learning: Discovering our students' strategies. Foreign Language Annals, 9(2), 117-130. https://doi.org/10.1111/j.1944-9720.1976.tb02637.x

Hosenfeld, C. (1977). A preliminary investigation of the reading strategies of successful and nonsuccessful second language learners. System, 5(2), 110-123.

Huang, S. (2016). Language learning strategies in context. The Language Learning Journal: Language Learning Strategies, 46(5), 647-659. https://doi.org/10.1080/09571736.2016.1186723

Johnson, D. W., \& Johnson, R. T. (2009). An educational psychology success story: Social interdependence Theory and Cooperative Learning. Educational Researcher, 38(5), 365-379. https://doi.org/10.3102/0013189x09339057

Jung, I., \& Lee, J. (2019). The effects of learner factors on MOOC learning outcomes and their pathways. Innovations in Education and Teaching International, Advance Online Publication. https://doi.org/10.1080/14703297.2019.1628800

Kayaoglu, M. N. (2013). Poor and good learners' language beliefs and their influence on their language learning strategy use. Novitas-ROYAL Research on Youth and Language, 7(1), 36-54. http://www.novitasroyal.org/Vol_7_1/kayaoglu.pdf

Khazaie, Z. M., \& Mesbah, Z. (2014). The relationship between extrinsic vs. intrinsic motivation and strategic use of language of Iranian intermediate EFL learners. Theory and Practice in Language Studies, 4(1), 99-109. https://doi.org/10.4304/tpls.4.1.99-109

Liem, A. D., Lau, S., \& Nie, Y. (2008). The role of self-efficacy, task value, and achievement goals in predicting learning strategies, task disengagement, peer relationship, and achievement outcome. Contemporary Educational Psychology, 33(4), 486-512. https://doi.org/10.1016/j.cedpsych.2007.08.001

Likitrattanaporn, W. (2018). A study of language learning strategies for practical use through the process of cooperative learning. International Journal of Educational Technology and Learning, 2(1), 35-44. https://doi.org/10.20448/2003.31.35.44

Lin, C.-H., Zhang, Y., \& Zheng, B. (2017). The roles of learning strategies and motivation in online language learning: A structural equation modeling analysis. Computers \& Education, 113, 75-85. https://doi.org/10.1016/j.compedu.2017.05.014

Little, D. (1991). Learner autonomy 1: Definitions, issues, and problems. Dublin: Authentik. 
Maddi, S. R. (2006). Hardiness: The courage to grow from stresses. The Journal of Positive Psychology, 1(3), 160-168. https://doi.org/10.1080/17439760600619609

Magogwe, J. M., \& Oliver, R. (2007). The relationship between language learning strategies, proficiency, age, and self-efficacy beliefs: A study of language learners in Botswana. System, 35(3), 338-352. https://doi.org/10.1016/j.system.2007.01.003

Mardia, K. V., Kent, J. T., \& Bibby, J. M. (1979). Multivariate analysis. Probability and mathematical statistics. Academic Press Inc.

Margolis, H., \& McCabe, P. P. (2006). Improving self-efficacy and motivation: What to do, what to say. Intervention in School and Clinic, 41(4), 218-227. https://doi.org/10.1177/10534512060410040401

Mochizuki, A. (1999). Language learning strategies used by Japanese university students. RELC Journal, 30(2), 101-113. https://doi.org/10.1177/003368829903000206

Moskovsky, C., Racheva, S., Assulaimani, T., \& Harkins, J. (2016). The L2 motivational self system and L2 achievement: A study of Saudi EFL learners. The Modern Language Journal, 100(3), 641-654. https//doi.org/10.1111/modl.12340 00267902/16/641-654

Moskovsky, C., Alrabai, F., Paolini, S., \& Ratcheva, S. (2013). The effects of teahers' motivational strategies on learners' motivation: A controlled investigation of second language acquisition. Language Learning, 63(1), 34-62. https://doi.org/10.1111/j.14679922.2012.00717.x

Namaziandost, E., Imani, A., \& Ziafar, M. (2020). An investigation of Iranian EFL teachers and learners' attitudes towards using language learning strategies. Global Journal of Foreign Language Teaching, 10(1), 65-71. https://doi.org/10.18844/gjflt.v10i1.4492

Nasihah, M., \& Cahyono, B. Y. (2017). Language learning strategies, motivation, and writing achievement of Indonesian EFL students. Arab World English Journal, 8(1), 250-263. https://dx.doi.org/10.24093/awej/vol8no1.18

Nosratinia, M., Saveiy, M., \& Zaker, A. (2014). EFL learners' self-efficacy, metacognitive awareness, and use of language learning strategies: How are they associated? Theory and Practice in Language Studies, 4(5), 1080-1092. https://doi.org/10.4304/tpls.4.5.1080-1092

O'Malley, J., \& Chamot, A. (1990). Learning strategies in second language acquisition. Cambridge University Press.

Oxford, R. L., \& Nyikos, M.(1989).Variables affecting choice of language learning strategies by university students. The Modern Language Journal, 73(3), 291-300. https://doi.org/10.1111/j.1540-4781.1989.tb06367.x

Oxford, R.L. (1990a). Strategy Inventory for Language Learning (SILL). Version 7.0. In R.L. Oxford, Language learning strategies: What every teacher should know (pp. 293-300). Boston: Heinle \& Heinle / Thomson Learning.

Oxford, R. L. (1990b). Language learning strategies: What every teacher should know. Issues in Applied Linguistics, 1(1), 115-120. https://escholarship.org/uc/item/1446j36q 
Oxford, R. L. (1993). Instructional implications of gender differences in language learning styles and strategies. Applied Language Learning, 4(1), 65-94.

Oxford, R. L., \& Burry-Stock, J. A. (1995). Assessing the use of language learning strategies worldwide with the ESL/EFL version of the Strategy Inventory for Language Learning (SILL). System, 23(1), 1-23. https://doi.org/10.1016/0346-251X(94)00047-A

Oxford, R. L. (2001). Language learning styles and strategies. In M. Celce-Murcia (Ed.), Teaching English as a second or foreign language (pp. 359-366). Boston: Heinle \& Heinle Press.

Oxford, R. L. (2017). Teaching and researching language learning strategies: Selfregulation in context (2nd ed.). Routledge.

Rubin, J. (1975). What the "good language learner" can teach us. TESOL Quarterly, 9(1), 41-51. https://doi.org/10.2307/3586011

Rubin, J. (1981). The study of cognitive processes in second language learning. Applied Linguistics, 2(2), 117-131. https://doi.org/10.1093/applin/2.2.117

Ryan, R. M., \& Deci, E. L. (2000). Intrinsic and extrinsic motivations: Classic definitions and new directions. Contemporary Educational Psychology, 25(1), 54-67. https://doi.org/10.1006/ceps.1999.1020

Shin, H., \& So, Y. (2018). The moderating role of socioeconomic status on motivation of adolescents' foreign language learning strategy use. System, 73, 71-79. https://doi.org/10.1016/j.system.2017.11.007

Slavin, R. E. (2011). Instruction based on cooperative learning. In R. E. Mayer \& P. A. Alexander (Eds.), Handbook of research on learning and instruction (pp. 388-404). https://doi.org/0.4324/9780203839089.ch17

Simons, J., Dewitte, S., \& Lens, W. (2000). Wanting to have vs. wanting to be: The effect of perceived instrumentality on goal orientation. British Journal of Psychology, 91(3), 335-351. https://doi.org/10.1348/0007126001618

Stern, H. H. (1975). What can we learn from the good language learner? Canadian Modern Language Review, 31(4), 304-319. https://doi.org/10.3138/cmlr.31.4.304

Taber, K.S. (2018). The use of Cronbach's alpha when developing and reporting research instruments in science education. Research in Science Education, 48, 12731296. https://doi.org/10.1007/s11165-016-9602-2

Teimouri, Y., Plonsky, L., \& Tabandeh, F. (2020). L2 grit: Passion and perseverance for second-language learning. Language Teaching Research, 1-26. Retrieved online at: https://doi.org/10.1177/1362168820921895

Teng, L. S., \& Zhang, L. J. (2016). A questionnaire-based validation of multidimensional models of self-regulated learning strategies. The Modern Language Journal, 100(3), 674-701. https://doi.org/10.1111/modl.12339

Teng, L. S., \& Zhang, L. J. (2018). Effects of motivational regulation strategies on writing performance: A mediation model of self-regulated learning of writing in English 
as a second/foreign language. Metacognition and Learning, 13(2), 213-240. https://doi.org/10.1007/s11409-017-9171-4

Tashakori, H. (2013). The relationship between motivation and language learning strategies in foreign language learning: A cognitive perspective. Modern Journal of Language Teaching Methods, 3(2), 37-47. http://mail.mjltm.org/browse.php?a_id=44\&sid=1\&slc_lang=en\&ftxt=1\#page=39

Tran, V. D., Nguyen, T. M. L., Van De, N., Soryaly, C., \& Doan, M. N. (2019). Does cooperative learning may enhance the use of students' learning strategies? International Journal of Higher Education, 8(4), 79-88. https://doi.org/10.5430/ijhe.v8n4p79

Vygotsky, L. S. (1978). Mind in society: The development of higher psychological processes. Cambridge: Harvard University Press.

Weinstein, C. E., \& Mayer, R. E. (1986). The teaching of learning strategies. In M. Wittrock (Ed.), The handbook of research on teaching (pp. 315-327). New York: Macmillan. The Teaching cf Learning Strategieslms.vocalerasmus.eu > mod_folder > content > Weinstei...

Weisburd, D. \& Britt, C. (2013). Statistics in criminal justice. Springer Science \& Business Media.

Wenden, A. (1998). Metacognitive knowledge and language learning. Applied Linguistics, 19(4), 515-537. https://doi.org/10.1093/applin/19.4.515

Wong, M. S. L. (2005). Language learning strategies and language self-efficacy: Investigating the relationship in Malaysia. RELC Journal, 36(3), 245-269. https://doi.org/10.1177/0033688205060050

$\mathrm{Xu}, \mathrm{X}$. (2011). The relationship between language learning motivation and the choice of language learning strategies among Chinese graduates. International Journal of English Linguistics, 1(2), 203-212. http://dx.doi.org/10.5539/ijel.v1n2p203

Yilmaz, C. (2010). The relationship between language learning strategies, gender, proficiency, and self-efficacy beliefs: A study of ELT learners in Turkey. Procedia Social and Behavioral Sciences, 2(2), 682-687. https://doi.org/10.1016/j.sbspro.2010.03.084

Yusuf, Q., Jusoh, Z., \& Yusuf, Y. Q. (2019). Cooperative learning strategies to enhance writing skills among second language learners. International Journal of Instruction, 12(1), 1399-1412. https://doi.org/10.29333/iji.2019.12189a

Zarei, A. A., \& Layeq, H. (2016). EFL learners' use of direct strategies in competitive and cooperative learning contexts. European Journal of Educational Research, 5(1), 19-25. https://doi.org/10.12973/eu-jer.5.1.19

Zhou, C., \& Intaraprasert, C. (2015). Language learning strategies employed by Chinese English-major pre-service teachers in relation to gender and personality types. English Language Teaching, 8(1), 155-169. https://doi.org/10.5539/elt.v8n1p155

Zimmerman, B. J. (2000). Self-efficacy: An essential motive to learn. Contemporary Educational Psychology, 25(1), 82-91. https://doi.org/10.1006/ceps.1999.1016 